\title{
Depletion of NK Cells Resistant to Ionizing Radiation Increases Mutations in Mice After Whole-body Irradiation
}

\author{
HAE-RAN PARK ${ }^{1}$ and UHEE JUNG ${ }^{2}$ \\ ${ }^{1}$ Research Division for Radiation Science, Korea Atomic Energy Research Institute (KAERI), Jeongeup, Republic of Korea; \\ ${ }^{2}$ Environmental Safety Research Team, Risk and Environmental Safety Research Division, \\ Korea Atomic Energy Research Institute (KAERI), Daejeon, Republic of Korea
}

\begin{abstract}
Background: Ionizing radiation is a very powerful genetic mutagenic agent. Although immune cells are very sensitive to radiation, their sensitivity varies between different types of immune cells. We hypothesized that radiation-resistant immune cells survive after irradiation and then play a role in removing mutant cells. Materials and Methods: Splenic lymphocytes and mice were irradiated with $\gamma$-rays. Cell populations were analyzed using flow cytometry after dyeing with antibodies and expression of B-cell lymphoma 2 (BCL2) was measured by western blot analysis. To deplete natural killer (NK) cells, anti-asialo GM1 antiserum was used. Micronuclei in polychromatic erythrocytes were measured by May-Grunwald/Giemsa staining. $\mathrm{H}-2 \mathrm{~Kb}$ loss variant in T-cells induced by irradiation of B6C3F1 mice was detected by flow cytometry. Results: When splenic lymphocytes were irradiated in vitro, B cells notably died, while NK cells did not. In vivo, on the third day after whole-body irradiation, the total number of lymphocytes in the spleen decreased rapidly, but the proportion of NK cells was approximately three times higher than that of the normal control group. In addition, it was confirmed that high expression of BCL2 in NK cells was maintained after irradiation, whereas that of B-cells was not. Removal of NK cells by injection with anti-asialo GMI antiserum immediately after irradiation increased the micronuclei of polychromatic erythrocytes in the bone marrow and the variant fraction with $H-2 k b$ loss in the spleen. Conclusion: These results provide important evidence that radioresistant NK cells apparently survive by escaping apoptosis in the early stages after irradiation, and work to
\end{abstract}

This article is freely accessible online.

Correspondence to: Hae-Ran Park, Ph.D., Korea Atomic Energy Research Institute 29 Geumgu-gil, Jeongeup-si, Jeollabuk-do 56212, Republic of Korea. E-mail: hrpark@kaeri.re.kr

Key Words: Ionizing radiation, NK cell, resistance, mutation, $\mathrm{H}-$ $2 \mathrm{~Kb}$ mutation, micronuclei. eliminate mutant cells resulting from $\gamma$-ray irradiation. Future studies are needed to reveal why NK cells are resistant to radiation and the in-depth mechanisms involved in the elimination of radiation-induced mutant cells.

Ionizing radiation increases the frequency of genetically mutated cells $(1,2)$ and this phenomenon is demonstrated in atomic-bomb survivors (3-5). However, the relationship between radiation dose and mutation frequency is still poorly understood.

Results of various studies have shown that mutant cells can be recognized and removed by immune cells in a process called immunosurveillance (6-9). Cytotoxic T cells (Tc cells) eliminate mutant cells whenever they detect mutated gene products as components of non-self major histocompatibility complex (MHC)-peptide complexes. Nevertheless, some kinds of mutant cell can escape from Tc cell recognition through down-regulating the expression of class I MHC molecules. Mutant cells that escape Tc-cell recognition can be dealt with by another important immune cell, the socalled natural killer $(\mathrm{NK})$ cell $(10,11)$.

The degree of sensitivity among various lymphocyte populations to irradiation may vary. B cells appear to be very sensitive to ionizing radiation, and rapidly decrease in number within 3 days, but recover to almost normal levels within 2 weeks after irradiation. Conversely, T cells, NKT cells, and NK cells are relatively resistant to ionizing radiation. For this reason, the proportion of radiationresistant cells in the spleen of irradiated mice was shown to be higher than that of normal mice until 2 weeks after irradiation (12-14). We wondered how this imbalance in the proportion of immune cells in the initial stages after irradiation would affect the time point (about a month later) at which the cell populations recovered after irradiation. Our previous study revealed that NKT cells that survived early after irradiation have a role in controlling radiation-induced abnormal immune responses in later stages (14).

The mechanism of elimination of abnormal cells by NK cells is regulated through a balance between activating 
receptors and inhibitory receptors on their membrane surface $(15,16)$. In this study, we investigated how NK cells affect the suppression of mutated cells induced by radiation. Our results provide insight into understanding the relationship between radiation and NK cells and the significance of NK cells in removing radiation-induced mutant cells in vivo.

\section{Materials and Methods}

Mice. C57BL/6 $\left(\mathrm{H}-2^{\mathrm{b}}\right)$ and $\mathrm{B} 6 \mathrm{C} 3 \mathrm{~F} 1\left[(\mathrm{~B} 6 \times \mathrm{C} 3 \mathrm{H}) \mathrm{F} 1 ; \mathrm{H}-2^{\mathrm{b} / \mathrm{k}}\right]$ mice were purchased from the Orient-Bio Inc. (Charles River Technology, Seongnam, Republic of Korea) were housed in specific pathogenfree conditions with free access to food and water.

Ethical statement. All experimental procedures were conducted according to the guidelines for the use and care of laboratory animals of Ministry of Health and Welfare, Republic of Korea. The protocols were approved by the Committee on The Use and Care of Animals at the Korea Atomic Energy Research Institute (KAERIIACUC-2018-014) and included criteria for euthanasia to minimize suffering.

Preparation of splenic lymphocytes and bone marrow cells. Lymphocytes from the spleen of C57BL/6 mice were separated using a density gradient centrifugation on a Ficoll-Hypaque solution (Sigma-Aldrich Co., St. Louis, MO, USA). The bone marrow cells from both femurs of mice were flushed from the femoral cavity with phosphate-buffered saline containing $10 \%$ fetal bovine serum (FBS). Red blood cells in bone marrow cells were removing using red blood cell lysis buffer. All cells were maintained in a Rosewell Park Memorial Institute 1640 medium (GIBCO BRL, Paisley, UK) supplemented with $20 \mathrm{mM}$ HEPES, 2 $\mathrm{mM}$ L-glutamine, $1 \mathrm{~m} \mathrm{M}$ pyruvate, $100 \mathrm{U} / \mathrm{ml}$ penicillin, $50 \mathrm{mg} / \mathrm{ml}$ streptomycin, $0.05 \mathrm{mM}$ 2-mercaptoethanol, $1 \%$ non-essential amino acid and $10 \%$ FBS (GIBCO BRL). These cells were used in subsequent experiments.

Radiation. For in vitro assay, splenic lymphocytes obtained from C57BL/6 mice were irradiated with 2 Gy of g-rays using a ${ }^{137} \mathrm{Cs}$ source irradiator (Gammacell 40 Exactor, Nordin International, Inc., Ottawa, Canada). For in vivo assay, 7-week-old mice were placed in containers and given whole-body irradiation with g-rays at a dose of $4 \mathrm{~Gy}(1.0 \mathrm{~Gy} / \mathrm{min})$ without anesthesia.

Determination of NK cells and B-cells in splenic lymphocytes after irradiation in vitro. To compare and analyze the radiation sensitivity of NK cells and B-cells in vitro, splenic lymphocytes from untreated C57BL/6 mice were irradiated in vitro with $\gamma$-ray at a dose of 2 Gy and were then incubated at $2 \times 10^{6}$ cells/24-well. After $0,3,6$, and 9 $\mathrm{h}$, the cultured lymphocytes were stained with fluorescein-labeled monoclonal antibody to cluster of differentiation (CD) 19 for analysis of B-cells, and phycoerythrin (PE)-labeled monoclonal antibody to NK1.1 for analysis of NK cells, and then were stained with $2 \mu \mathrm{g} / \mathrm{ml}$ propidium iodide at room temperature for 30 minutes. These cells were analyzed using a FACSCalibur flow cytometer (BD Biosciences, San Jose, CA, USA). A fluorescence histogram of at least 20,000 cells was performed for each sample. Monoclonal antibodies NK1.1 and CD19 and isotype IgG2b antibody were purchased from BD Biosciences.
Determination of the percentage of $\mathrm{NK}$ cells in the spleen after whole-body irradiation. Seven-week-old C57BL/6 mice were given whole-body irradiation with g-rays at a dose of $4 \mathrm{~Gy}(1.0 \mathrm{~Gy} / \mathrm{min})$ without anesthesia. Three, 7 , and 14 days after radiation exposure, splenic lymphocytes isolated from these mice were stained with PElabeled NK1.1 monoclonal antibody for 30 minutes at room temperature, and then were analyzed using a FACSCalibur flow cytometer.

Separation of NK cells and B-cells from splenic lymphocytes and western blot analysis. NK cell and B cells were purified from the splenic lymphocytes of C57BL/6 using a magnetic cell sorter (Miltenyi Biotec, Bergisch Gladbach, Germany) according to the manufacturer's procedures, and the purity of the cells was $>98 \%$. The antibodies used were monoclonal rat anti-CD49b (DX5) and rat anti-CD19 conjugated to magnetic cell-sorting colloidal superparamagnetic microbeads (Miltenyi Biotec). Separated NK cells and $\mathrm{B}$ cells were irradiated with $\gamma$-rays at a dose of $2 \mathrm{~Gy}$.

To analyze B-cell lymphoma 2 (BCL2) expression, lysates from B-cells and NK cells were prepared using RIPA lysis buffer (Thermo Scientific, Rockford, IL, USA) containing $10 \mathrm{mM}$ phenylmethanesulphonylfluoride, $10 \mathrm{mM}$ sodium fluoride, $1 \mathrm{mM}$ sodium orthovanadate and a complete protease inhibitor cocktail (Sigma-Aldrich, St. Louis, MO, USA) for $30 \mathrm{~min}$ on ice. Equal amounts of protein were boiled in a Laemmli sample buffer containing 2-mercaptoethanol (Bio-Rad Laboratories, Inc., Hercules, CA, USA), and then separated on sodium dodecyl sulphatepolyacrylamide gel. After electrophoresis, proteins were transferred onto a polyvinylidene fluoride (Amersham, Freiburg, Germany). The membranes were blocked with $50 \mathrm{~g} / \mathrm{l}$ skimmed milk or bovine serum albumin in tris-buffered saline containing $1 \mathrm{ml} / 1$ Tween-20 and then were incubated overnight at $4^{\circ} \mathrm{C}$ with primary antibodies against BCL 2 or $\beta$-actin (Cell Signaling, Danvers, MA, USA). After washing with tris-buffered saline containing $1 \mathrm{ml} / 1$ Tween-20, the membranes were incubated with anti-rabbit IgG antibody or antimouse IgG conjugated with horseradish peroxidase-conjugated antimouse IgG (Cell Signaling) for $1 \mathrm{~h}$, and developed using ECL western blot detection reagents (Millipore, Billerica, MA, USA).

Depletion of NK cells in vivo. To deplete mice of NK cells after whole-body irradiation, $20 \mathrm{ml}$ rabbit antibody against asialo-GM1 (Wako Chemicals, Osaka, Japan) was intraperitoneally injected immediately after irradiation and then again 1 and 5 days after irradiation (45).

Detection of micronucleated polychromatic erythrocytes (MN PCEs) of bone marrow. At 24 hours after whole-body irradiation, bone marrow cells collected from the C57BL/6 mice were suspended in $50 \mathrm{ml}$ FBS and then were used for smear preparation. Three smears of bone marrow cells were prepared from each mouse. After airdrying, the smeared slides were fixed by methanol and then were stained by May-Grunwald/Giemsa. With this method, PCEs stain reddish-blue and normochromatic erythrocytes stain orange, while nuclear material is a dark-purple color. From each animal, 3,000 PCEs $(1,000$ per slide) were examined under $\times 1,000$ magnification using a microscope and the percentage of MN PCEs was calculated.

Detection of $H-2 K^{b}$ loss variant in $T$-cells. Twelve days after wholebody irradiation of $\mathrm{H}-2^{\mathrm{b} / \mathrm{k}} \mathrm{F} 1(\mathrm{~B} 6 \mathrm{C} 3 \mathrm{~F} 1)$ mice, the frequency of $\mathrm{H}-$ $2 \mathrm{~K}^{\mathrm{b}}$-negative $\mathrm{T}$-cells induced by irradiation were detected. Splenic 
$\mathbf{A}$

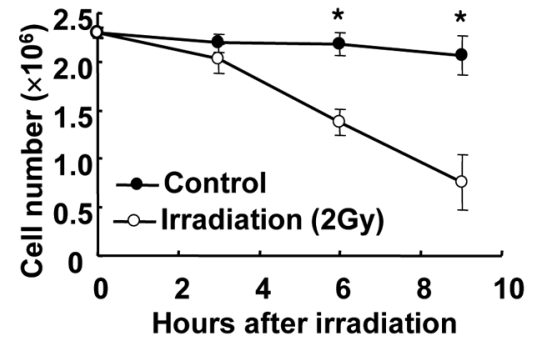

Total spleen cells

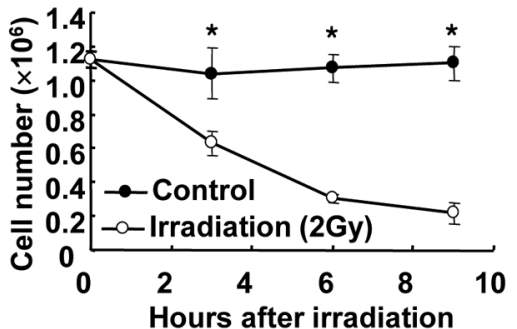

NK cells

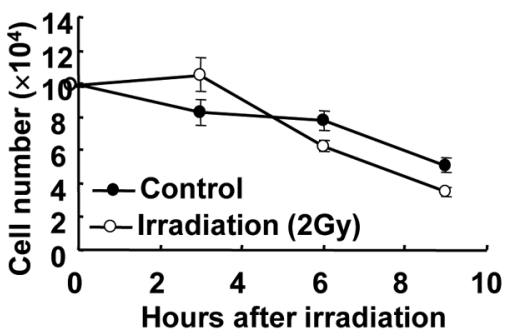

B

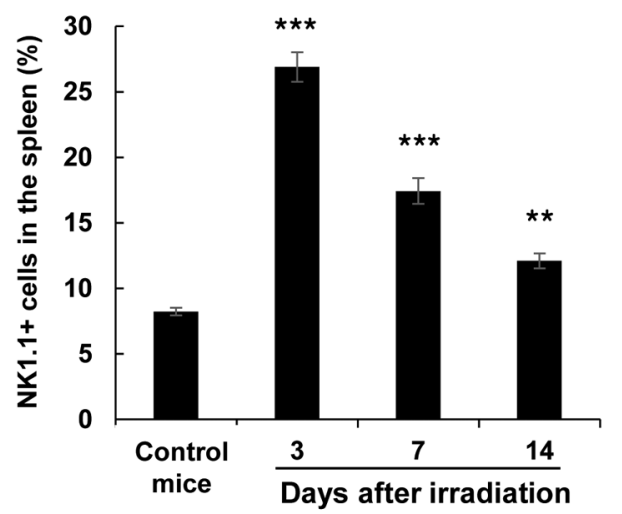

C

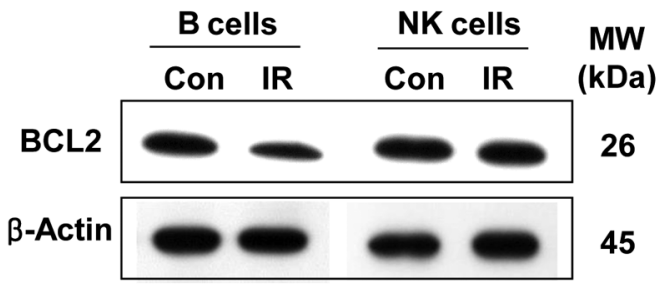

Figure 1. Natural killer (NK) cells are more resistant to radiation-induced apoptosis than B cells. A: The splenic lymphocytes from untreated C57BL/6 mice were incubated at $2 \times 10^{6}$ cells/24-well and treated with or without 2 Gy gamma irradiation. After 0, 3, 6, and 9 hours, cells were harvested and stained with antibodies to CD19 and NK1.1 and then with $2 \mu \mathrm{g} / \mathrm{ml}$ propidim iodide. The number of surviving cells in cell subsets in each well was analyzed by flow cytometry. The values represent the mean \pm S.D. for at least three mice. B: On days 3, 7, and 14 days after whole-body irradiation of mice, the proportion of NK1.1+ cells among the spleen cells was measured by flow cytometry. Significantly different at: *p<0.01, ${ }^{* *} p<0.005$ and $* * * p<0.001$ compared with the control group or untreated mice. C: Expression of BCL2 was analyzed by western blot as described in the Materials and Methods.

lymphocytes were prepared and stained with PE-conjugated anti-H$2 \mathrm{~K}^{\mathrm{b}}$ and fluorescein isothiocyanate-conjugated anti-CD3. Labeled cells were suspended in buffer containing $10 \mathrm{mg} / \mathrm{ml}$ propidium iodide and analyzed with flow cytometry. Fluorescence data from a minimum of $1 \times 10^{5}$ lymphocyte-gated events were analyzed. The mutation frequency for $\mathrm{H}-2 \mathrm{~K}^{\mathrm{b}}$-deficient $\mathrm{CD}^{+}{ }^{+} \mathrm{T}$-cells was calculated as: Number of $\mathrm{CD}^{+}{ }^{+} \mathrm{H}-2 \mathrm{~K}^{\mathrm{b}}$-negative lymphocytes/total number of $\mathrm{CD}^{+}$lymphocytes.

Statistical analyses. All experiments were performed at least three times independently. All data are expressed as the mean \pm S.D. and differences were statistically analyzed using the two-tailed Student's $t$-test.

\section{Results}

NK cells were more resistant to ionizing radiation. Although lymphocytes are generally highly radiosensitive, NK $1.1^{+} \mathrm{T}$ cells were shown in a previous study to be more resistant than conventional T-cells (14). In this study, we attempted to determine whether NK cells exhibit resistance to radiation- induced apoptosis. As is shown in Figure 1A, in vitro radiation exposure of splenic lymphocytes resulted in a significant reduction in the number of surviving B cells from 3 to $9 \mathrm{~h}$ after irradiation. By way of contrast, the number of NK cells after irradiation was equivalent to those without irradiation, although the number of surviving NK cells declined spontaneously following culturing, even without irradiation. This result indicates that NK cells are more resistant to ionizing radiation than $\mathrm{B}$ cells.

In mice, total cell numbers in the spleen dramatically decreased to about $5.1 \%$ on the third day after whole-body irradiation (normal mice: $84.8 \pm 7.79 \times 10^{6}$ cells/spleen, irradiated mice: $4.33 \pm 0.45 \times 10^{6}$ cells/spleen). However, the percentage of $\mathrm{NK} 1.1^{+}$cells in the spleen was significantly increased by whole-body irradiation (Figure 1B). The percentage of $\mathrm{NK} 1.1^{+}$cells on day 3 after irradiation was about three times higher than that of normal mice, and gradually decreased to 1.5 times higher in the second week 


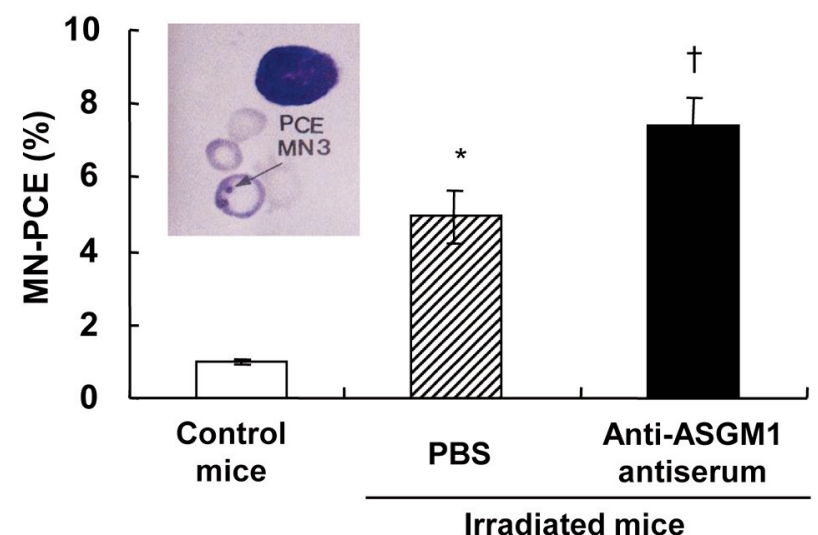

Figure 2. Comparison of micronucleated polychromatic erythrocytes (MN-PCEs) in bone marrow cells of irradiated mice deficient in natural killer (NK) cells. A: For depletion of NK cells, anti-asialo-GM1 antiserum was injected immediately after whole-body irradiation of C57BL/6 mice and then again 24 hours later. After 3 days, the depletion of NK cells in splenic lymphocytes was confirmed by flow cytometry. $B$ : Twenty-four hours after irradiation, bone marrow samples were collected from the femurs and bone marrow cells were smeared following resuspension in fetal bovine serum. The slides were stained by MayGrunwald/Giemsa. From each animal 3,000 PCEs were examined for $M N$ cells. Significantly different at $p<0.001$ compared with: *control and tphosphate-buffered saline (PBS)-treated irradiated mice.

after irradiation. This indicates that NK cells remained unimpaired by radiation compared to other cells in the spleen.

In order to determine the reason why NK cells exhibit enhanced radiation resistance, we assessed BCL2 expression, which has been determined to protect the lymphocytes against radiation-induced apoptosis $(17,18)$. Figure 1C shows that the NK cells maintained a constant level of BCL2 expression after irradiation, whereas its expression markedly decreased in B cells. These results suggest that NK cells are resistant to radiation-induced apoptosis, possibly due to high expression of BCL2.

Irradiated mice deficient in NK cells had an increased frequency of mutant cells. To investigate whether NK cells are involved in the elimination of mutant cells occurring after irradiation, NK cells in irradiated mice were depleted using anti-asialo GM1 antiserum as described in the Materials and Methods section. It was confirmed that NK cells were removed by more than $90 \%$ using flow cytometry (Figure 2). We investigated the effect of NK cell depletion on the frequency of chromosomal aberrations and the incidence of mutant lymphocytes lacking expression of class I MHC molecules in irradiated mice. Firstly, the increase in the frequency of chromosomal aberrations by ionizing radiation was measured using the micronucleus assay of PCEs as an indicator of bone marrow toxicity induced by ionizing radiation $(19,20)$. The highest frequency of $\mathrm{MN}$
PCEs of bone marrow cells were found at 24 hours after irradiation (data not shown). As shown in Figure 2B, the frequency of MN PCEs was at about $1 \%$ in control mice but was increased six-fold by irradiation. Irradiated mice injected with anti-asialo GM1 antiserum, i.e. deficient in NK cells, had higher levels of MN PCEs as compared with those in irradiated mice injected with phosphate-buffered saline $(p<0.001)$. Secondly, in order to investigate lymphocytes lacking class I MHC molecules because of ionizing radiation, we measured $\mathrm{H}-2 \mathrm{~K}^{\mathrm{b}}$-deficient $\mathrm{CD}^{+}$cells in B6C3F1 mice using flow cytometry (Figure 3). The frequency of the $\mathrm{H}-2 \mathrm{~K}^{\mathrm{b}}$-deficient $\mathrm{CD}^{+}$cells was markedly increased by irradiation. In irradiated mice injected with anti asialo-GM1 antiserum, the increase of $\mathrm{H}-2 \mathrm{~K}^{\mathrm{b}}$-deficient in $\mathrm{CD}^{+}$cells was significant compared with control irradiated mice. These results suggest that NK cells play a significant role in eliminating cells with chromosomal aberration after irradiation of lymphocytes lacking class I MHC molecules.

\section{Discussion}

There are many reports that exposure to ionizing radiation reduces the number of immune cells and induces abnormal immune responses $(12,21-23)$. Different types of immune cells have been shown to have different sensitivities to radiation, with $\mathrm{B}$-cells being most sensitive and $\mathrm{NK}$ and $\mathrm{NKT}$ cells being most resistant $(13,14,24)$. In comparison of $\mathrm{T}$ cell subsets, $\mathrm{CD}^{+} \mathrm{T}$ cells were shown to be more sensitive than the $\mathrm{CD}^{+} \mathrm{T}$ cells (13). There have been reports that the ability of lymphocytes to protect against radiation-induced apoptosis is associated with high expression of BCL2 $(17,18)$. Tamada and colleagues reported that BCL2 expression in NK1.1 ${ }^{+} \mathrm{T}$ cells was higher than that observed in conventional $\mathrm{T}$ cells (25), and it was confirmed that NK cells expressed higher levels of BCL2 than B cells in the results of this study. BCL2 is anti-apoptotic regulatory protein, and prevents apoptotic cell death by reducing the release of apoptogenic factors such as cytochrome $c$ and apoptosis-inducing factor from the intermembrane space of mitochondria $(26,27)$.

Radioresistant immune cells such as NK cells and NKT cells are present at a high frequency early after irradiation, and we were curious about what these cells do. Our previous study showed that radioresistant NKT-cells may play a role in the balance responses of helper $\mathrm{T}$ (Th) 1 and Th2 cells after ionizing irradiation (14). In the present study, we hypothesized that radioresistant NK cells serve to remove mutant cells generated by ionizing radiation. Ionizing radiation is a powerful genotoxic agent, inducing gene mutations and chromosomal aberrations $(1,2)$. NK cells are the first line of the innate defense against infected or mutant cells, as well as cancer cells $(28,29)$. The mechanism by which activated NK cells eliminate abnormal mutant cells is through interferon- $\gamma$ production and antibody-dependent 
cellular cytotoxicity $(30,31)$, and these activated NK cells play an important role in coordinating and optimizing both innate and adaptive immune responses $(32,33)$.

To test our hypothesis, we firstly measured the frequency of PCEs with MN following irradiation. The MN test is now recognized as one of the most reliable assays for genotoxic carcinogens. The principle of MN formation in PCEs is that when immature red blood cells are affected by a mutagen such as ionizing radiation, the chromosome is broken and cannot be further differentiated, and remains as a fragment in the cytoplasm in mature erythrocytes, which are then called MN PCEs $(19,20$, 34). For this reason, the frequency of MN PCEs in bone marrow is a validated index of chromosomal aberrations induced by ionizing radiation. The frequency of MN cells was increased in a dose-dependent manner after irradiating cultured human lymphocytes in several studies (35-37). Our study showed that NK cell deficiency in irradiated mice increased the frequency of MN PCEs. However, we do not yet know the mechanism by which NK cells cause the elimination of MN PCEs.

Removal of mutant cells is accomplished not only by NK cells but also by cytotoxic T-cells through recognizing class I MHC antigen of mutant cells $(8,16,32,38)$. However, a problem is that infected cells and malignant cells often exploit inhibition of class I MHC expression in order to evade surveillance by cytotoxic T cells $(38,39)$. Eventually, abnormal cells that escape $\mathrm{T}$ cell recognition can be dealt with by NK cells. Although cytotoxic T cells have memory capacity for antigens, elimination of abnormal cells that do not express class I MHC by NK cells is considered very important. NK cell-mediated elimination of such cells is regulated by a balance between signals generated from activating receptors and inhibitory receptors $(15,16,40-42)$. Nevertheless, a recent study showed there to be no significant effects of radiation on the frequency of T-cells with mutations that lacked HLA-A expression in atomic-bomb survivors, despite evidence of an increased frequency of cells bearing genetic mutations (43). However, it was assumed that these results were probably due to the elimination of any HLA-A-mutant cells that were generated by radiation, and this assumption is supported by evidence that NK cells can kill autologous cells that lack self class I MHC molecules $(44,45)$. In our study, we confirmed that $\mathrm{H}-2 \mathrm{~K}^{\mathrm{b}}$ loss variant $\mathrm{T}$ cells were observed more frequently in irradiated mice depleted of $\mathrm{NK}$ cells than in control irradiated mice. This finding is similar to the observation that the frequency of HLA-A2-negative cells were reduced as the result of NK cell addition (46).

The detailed mechanisms by which NK cells promote the elimination of mutant cells induced by $\gamma$-rays have not yet been resolved and there is a clear need for more studies on this aspect. However, we reached the conclusion that NK cells that avoided apoptosis in the early stages after irradiation play a major role in eliminating the mutant cells through high expression of the anti-apoptosis protein BCL2.
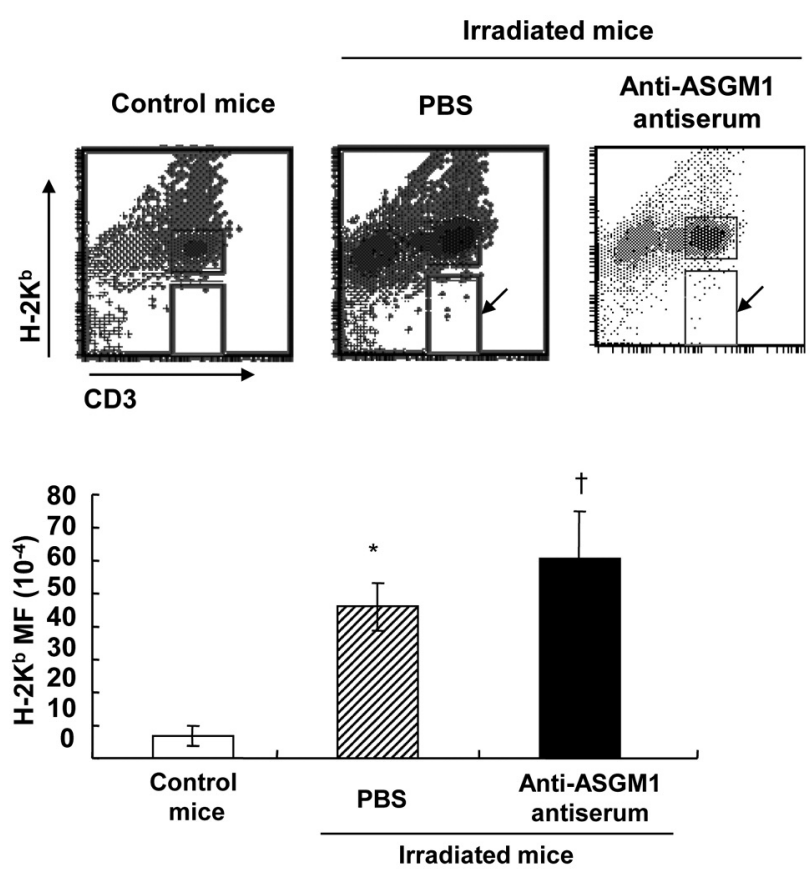

Figure 3. Comparison of mutation frequency $(M F)$ of $\mathrm{H}-2 \mathrm{~Kb}$ in spleen cells of irradiated B6C3F1 mice injected with anti-asialo GM1 to induce depletion of natural killer (NK) cells. Splenic lymphocytes were obtained from control (left), irradiated (middle), and NK cell-depleted irradiated (right) mice at 12 days after irradiation and stained with anti-CD3 and anti-H-2K . Fluorescence data from a minimum of $1 \times 10^{5}$ lymphocytes were analyzed. Significantly different at $p<0.001$ compared with: *control and ${ }^{\dagger}$ phosphate-buffered saline (PBS)-treated irradiated mice.

\section{Conflicts of Interest}

The Authors declare that they have no competing interests in regard to this study.

\section{Authors' Contributions}

HRP carried out conceptualization, all experiments, data collection and writing. UHJ participated in the design of the study. Both Authors read and approved the published version of the article.

\section{Acknowledgements}

This work was supported by grants from the Nuclear R\&D program of the Ministry of Science \& ICT (MSTI) of Korea and internal R\&D project of KAERI (523260-20), Republic of Korea. The funders had no role in designing and executing the experiments.

\section{References}

1 Das G, Stewart JW and Sherman F: Mutational alterations induced in yeast by ionizing radiation. Mutat Res 163(3): 233-245, 1986. PMID: 3023992. DOI: 10.1016/0027-5107(86)90021-7

2 Liber HL, Call KM and Little JB: Molecular and biochemical analyses of spontaneous and X-ray-induced mutants in human 
lymphoblastoid cells. Mutat Res 178(1): 143-153, 1987. PMID: 3033487. DOI: 10.1016/0027-5107(87)90096-0

3 Neel JV, Satoh C and Myers R: International commission for protection against environmental mutagens and carcinogens. Report of a workshop on the application of molecular genetics to the study of mutation in the children of atomic bomb survivors. Mutat Res 291(1): 1-20, 1993. PMID: 7678910. DOI: 10.1016/0165-1161(93)90012-o

4 Satoh C, Takahashi N, Asakawa J, Kodaira M, Kuick R, Hanash SM and Neel JV: Genetic analysis of children of atomic bomb survivors. Environ Health Perspect 104(Suppl 3): 511-519, 1996. PMID: 8781374. DOI: 10.1289/ehp.96104s3511

5 Nakamura N: Genetic effects of radiation in atomic-bomb survivors and their children: Past, present and future. J Radiat Res 47(Suppl B): B67-B73, 2006. PMID: 17019054. DOI: 10.1269/jrr.47.b67

6 Burnet FM: The concept of immunological surveillance. Prog Exp Tumor Res 13: 1-27, 1970. PMID: 4921480. DOI: $10.1159 / 000386035$

7 Smyth MJ, Thia KY, Street SE, Cretney E, Trapani JA, Taniguchi M, Kawano T, Pelikan SB, Crowe NY and Godfrey DI: Differential tumor surveillance by natural killer (NK) and NKT cells. J Exp Med 191(4): 661-668, 2000. PMID: 10684858. DOI: $10.1084 /$ jem.191.4.661

8 Dunn GP, Bruce AT, Ikeda H, Old LJ and Schreiber RD: Cancer immunoediting: From immunosurveillance to tumor escape. Nat Immunol 3(11): 991-998, 2002. PMID: 12407406. DOI: 10.1038/ni1102-991

9 Russell JH and Ley TJ: Lymphocyte-mediated cytotoxicity. Annu Rev Immunol 20: 323-370, 2002. PMID: 11861606. DOI: 10.1146/annurev.immunol.20.100201.131730

10 Vivier E, Tomasello E, Baratin M, Walzer T and Ugolini S: Functions of natural killer cells. Nat Immunol 9(5): 503-510, 2008. PMID: 18425107. DOI: $10.1038 /$ ni1582

11 Waldhauer I and Steinle A: NK cells and cancer immunosurveillance. Oncogene 27(45): 5932-5943, 2008. PMID: 18836474. DOI: $10.1038 /$ onc.2008.267

12 Chambers KA, Harrington NP, Ross WM and Filion LG: Relative alterations in blood mononuclear cell populations reflect radiation injury in mice. Cytometry 31(1): 45-52, 1998. PMID: 9450524.

13 Kajioka EH, Andres ML, Li J, Mao XW, Moyers MF, Nelson GA, Slater JM and Gridley DS: Acute effects of whole-body proton irradiation on the immune system of the mouse. Radiat Res 153(5 Pt 1): 587-594, 2000. PMID: 10790280. DOI: 10.1667/0033-7587(2000)153[0587:aeowbp]2.0.co;2

14 Park HR, Jo SK and Paik SG: The NK1.1+T cells alive in irradiated mice play an important role in a Th1/Th2 balance. Int J Radiat Biol 82(3): 161-170, 2006. PMID: 16638713. DOI: $10.1080 / 09553000600632873$

15 Lanier LL: On guard - activating NK cell receptors. Nat Immunol 2(1): 23-27, 2001. PMID: 11135574. DOI: $10.1038 / 83130$

16 Janeway CA Jr and Medzhitov R: Innate immune recognition. Annu Rev Immunol 20: 197-216, 2002. PMID: 11861602. DOI: 10.1146/annurev.immunol.20.083001.084359

17 Sentman CL, Shutter JR, Hockenbery D, Kanagawa O and Korsmeyer SJ: bcl-2 inhibits multiple forms of apoptosis but not negative selection in thymocytes. Cell 67(5): 879-888, 1991. PMID: 1835668. DOI: 10.1016/0092-8674(91)90361-2

18 Chao DT, Linette GP, Boise LH, White LS, Thompson CB and Korsmeyer SJ: Bcl-XL and Bcl-2 repress a common pathway of cell death. J Exp Med 182(3): 821-828, 1995. PMID: 7650488. DOI: $10.1084 /$ jem.182.3.821

19 Schlegel R, MacGregor JT and Everson RB: Assessment of cytogenetic damage by quantitation of micronuclei in human peripheral blood erythrocytes. Cancer Res 46(7): 3717-3721, 1986. PMID: 3708597.

20 Suzuki Y, Nagae Y, Li J, Sakaba H, Mozawa K, Takahashi A and Shimizu H: The micronucleus test and erythropoiesis. Effects of erythropoietin and a mutagen on the ratio of polychromatic to normochromatic erythrocytes (P/N ratio). Mutagenesis 4(6): 420-424, 1989. PMID: 2516221. DOI: 10.1093/mutage/4.6.420

21 Akiyama M: Late effects of radiation on the human immune system: An overview of immune response among the atomicbomb survivors. Int J Radiat Biol 68(5): 497-508, 1995. PMID: 7490500. DOI: 10.1080/09553009514551491

22 Kusunoki Y and Hayashi T: Long-lasting alterations of the immune system by ionizing radiation exposure: implications for disease development among atomic bomb survivors. Int J Radiat Biol 84(1): 1-14, 2008. PMID: 17852558. DOI: 10.1080/ 09553000701616106

23 Park HR and Jo SK: Lasting effects of an impairment of Th1like immune response in $\gamma$-irradiated mice: A resemblance between irradiated mice and aged mice. Cell Immunol 267(1): 1-8, 2011. PMID: 21092942. DOI: 10.1016/j.cellimm.2010. 10.004

24 Kimura M, Watanabe H, Ohtsuka K, Iiai T, Tsuchida M, Sato S and Abo T: Radioresistance of intermediate TCR cells and their localization in the body of mice revealed by irradiation. Microbiol Immunol 37(8): 641-652, 1993. PMID: 8246826. DOI: 10.1111/j.1348-0421.1993.tb01687.x

25 Tamada K, Harada M, Abe K, Li T and Nomoto K: IL-4producing NK1.1+ T cells are resistant to glucocorticoid-induced apoptosis: Implications for the Th1/Th2 balance. J Immunol 161(3): 1239-1247, 1998. PMID: 9686584.

26 Tsujimoto Y and Shimizu S: Bcl-2 family: life-or-death switch. FEBS Lett 466(1): 6-10, 2000. PMID: 10648802. DOI: 10.1016/s0014-5793(99)01761-5

27 Youle RJ and Strasser A: The BCL-2 protein family: Opposing activities that mediate cell death. Nat Rev Mol Cell Biol 9(1): 47-59, 2008. PMID: 18097445. DOI: 10.1038/nrm2308

28 Guo H, Kumar P and Malarkannan S: Evasion of natural killer cells by influenza virus. J Leukoc Biol 89(2): 189-194, 2011. PMID: 20682623. DOI: 10.1189/jlb.0610319

29 Jost S and Altfeld M: Control of human viral infections by natural killer cells. Annu Rev Immunol 31: 163-194, 2013. PMID: 23298212. DOI: 10.1146/annurev-immunol-032712100001

30 Alderson KL and Sondel PM: Clinical cancer therapy by NK cells via antibody-dependent cell-mediated cytotoxicity. J Biomed Biotechnol 2011: 379123, 2011. PMID: 21660134. DOI: $10.1155 / 2011 / 379123$

31 Wang W, Erbe AK, Hank JA, Morris ZS and Sondel PM: NK Cell-mediated antibody-dependent cellular cytotoxicity in cancer immunotherapy. Front Immunol 6: 368, 2015. PMID: 26284063. DOI: $10.3389 /$ fimmu.2015.00368

32 Vivier E, Raulet DH, Moretta A, Caligiuri MA, Zitvogel L, Lanier LL, Yokoyama WM and Ugolini S: Innate or adaptive immunity? The example of natural killer cells. Science 331(6013): 44-49, 2011. PMID: 21212348. DOI: 10.1126/science.1198687 
33 Morvan MG and Lanier LL: NK cells and cancer: You can teach innate cells new tricks. Nat Rev Cancer 16(1): 7-19, 2016. PMID: 26694935. DOI: $10.1038 / \mathrm{nrc} .2015 .5$

34 Mavournin KH, Blakey DH, Cimino MC, Salamone MF and Heddle JA: The in vivo micronucleus assay in mammalian bone marrow and peripheral blood. A report of the U.S. environmental protection agency gene-tox program. Mutat Res 239(1): 29-80, 1990. PMID: 2195332. DOI: 10.1016/0165-1110(90)90030-f

35 Gantenberg HW, Wuttke K, Streffer C and Müller WU: Micronuclei in human lymphocytes irradiated in vitro or in vivo. Radiat Res 128(3): 276-281, 1991. PMID: 1961924.

36 Vral A, Thierens H and De Ridder L: In vitro micronucleuscentromere assay to detect radiation-damage induced by low doses in human lymphocytes. Int J Radiat Biol 71(1): 61-68, 1997. PMID: 9020964 . DOI: 10.1080/095530097144427

37 Wojcik A, Kowalska M, Bouzyk E, Buraczewska I, Kobialko G, Jarocewicz N and Szumiel I: Validation of the micronucleuscentromere assay for biological dosimetry. Genetics and Molecular Biology 23(4): 1083-1085, 2019. DOI: 10.1590/ S1415-47572000000400055

38 Kärre K, Ljunggren HG, Piontek G and Kiessling R: Selective rejection of $\mathrm{H}$-2-deficient lymphoma variants suggests alternative immune defence strategy. Nature 319(6055): 675678, 1986. PMID: 3951539. DOI: 10.1038/319675a0

39 Garrido F, Ruiz-Cabello F, Cabrera T, Pérez-Villar JJ, LópezBotet M, Duggan-Keen M and Stern PL: Implications for immunosurveillance of altered HLA class I phenotypes in human tumours. Immunol Today 18(2): 89-95, 1997. PMID: 9057360. DOI: 10.1016/s0167-5699(96)10075-x

40 Karlhofer FM, Ribaudo RK and Yokoyama WM: MHC class I alloantigen specificity of Ly-49+ IL-2-activated natural killer cells. Nature 358(6381): 66-70, 1992. PMID: 1614533. DOI: $10.1038 / 358066 \mathrm{a} 0$

41 Wagtmann N, Rajagopalan S, Winter CC, Peruzzi M and Long EO: Killer cell inhibitory receptors specific for HLA-C and HLA-B identified by direct binding and by functional transfer. Immunity 3(6): 801-809, 1995. PMID: 8777725. DOI: 10.1016/ 1074-7613(95)90069-1
42 Long EO: Regulation of immune responses through inhibitory receptors. Annu Rev Immunol 17: 875-904, 1999. PMID: 10358776. DOI: 10.1146/annurev.immunol.17.1.875

43 Kushiro J, Hirai Y, Kusunoki Y, Kyoizumi S, Kodama Y, Wakisaka A, Jeffreys A, Cologne JB, Dohi K and Nakamura N: Development of a flow-cytometric HLA-A locus mutation assay for human peripheral blood lymphocytes. Mutat Res 272(1): 1729, 1992. PMID: 1380116. DOI: 10.1016/0165-1161(92)90005-7

44 Ohlén C, Höglund P, Sentman CL, Carbone E, Ljunggren HG, Koller B and Kärre K: Inhibition of natural killer cell-mediated bone marrow graft rejection by allogeneic major histocompatibility complex class I, but not class II molecules. Eur J Immunol 25(5): 1286-1291, 1995. PMID: 7774631. DOI: 10.1002/eji.1830250523

45 Kusunoki Y, Kyoizumi S, Honma M, Kubo Y, Ohnishi H, Hayashi T and Seyama T: NK-mediated elimination of mutant lymphocytes that have lost expression of MHC class I molecules. J Immunol 165(7): 3555-3563, 2000. PMID: 11034355. DOI: $10.4049 /$ jimmunol.165.7.3555

46 Kusunoki Y, Kyoizumi S, Kubo Y, Hayashi T and MacPhee DG: Possible role of natural killer cells in negative selection of mutant lymphocytes that fail to express the human leukocyte antigen-A2 allele. Mutat Res 476(1-2): 123-132, 2001. PMID: 11336989. DOI: 10.1016/s0027-5107(01)00106-3
Received February 5, 2021

Revised March 19, 2021

Accepted March 22, 2021 